\title{
Advancements in 3D Printing Technology: Applications and Options for Prosthetic Dentistry
}

\author{
Özay Önöral' (D), Amr Abugofa² (D)
}

'Department of Prosthetic Dentistry, Near East University Faculty of Dentistry, Nicosia, Cyprus ${ }^{2}$ Department of Prosthetic Dentistry, Near East University Faculty of Dentistry, Nicosia, Cyprus

ORCID iDs of the authors: Ö.0̈. 0000-0002-5264-9376; A. A. 0000-0002-280I-I08I.

Cite this article as: Önöral Ö, Abugofa A. Advancements in 3D Printing Technology: Applications and Options for Prosthetic Dentistry. Cyprus J Med Sci 2020; 5(2): 176-82.

\begin{abstract}
The use of additive manufacturing systems in dentistry is becoming a widespread phenomenon. Additive manufacturing technology is defined as the fabrication of a 3D model or prototype by agglomerating the biomaterials layer by layer in a specific pattern dictated by the computer-aided design software. With the aid of this technology; structures with superior biocompatibility are rapidly, precisely, and inexpensively fabricated for direct medical utilization. In contemporary dentistry, manifold additive manufacturing techniques have been developed for the fabrication of fixed prosthetic restorations, removable dentures, surgical guides, individualized implants, custom impression trays, and anatomical models. Of these; stereolithography, selective laser sintering, selective laser melting, fused deposition modeling, and electron beam melting are commonly used. However, scientific data regarding their material options and working principles are still insufficient. Therefore, the aim of this review is to study the current status of common additive manufacturing techniques in prosthetic dentistry.
\end{abstract}

Keywords: 3D printing, additive manufacturing, computer-aided manufacturing rapid prototyping

\section{INTRODUCTION}

Additive manufacturing ( $A M)$, which is more colloquially known as either 3-dimensional (3D) printing or rapid prototyping (RP), was first expressed by Charles Hull in the late 1980s (I). The fundamental concept of additive manufacturing is to fabricate a 3D model by depositing biomaterials layer by layer in a specific pattern dictated by the computer-aided design software (I-10). The popularity of AM techniques is deliberately increasing as they allow fast, precise, and cost-effective fabrication of highly customized functional structures for direct medical utilization (2). Moreover, the amount of waste is significantly reduced (I). With all these opportunities, there is a considerable shift from standardized to personalized dentistry as manufacturing of custom structures including craniomaxillofacial implants, surgical guides, root-analogue implants, impression trays, polymer-matrix composites, and anatomical models is feasible through this disruptive innovation (I-3).

To date, numerous novel AM techniques have been developed which can present superior print qualities. The five leading technologies prominent in contemporary dentistry are stereolithography (SLA) (I-5, 7, 8, 10-14), selective laser sintering $(\operatorname{SLS})(I-5,9,11)$, selective laser melting $(\operatorname{SLM})(2,3,5,9,11)$, fused deposition modeling (FDM) $(I-5,7,10$, II, I5), and electron beam melting $(E B M)(2,3,9,11)$. Each adopts different methods of fabrication. However, the fabrication process through AM technologies generally consists of several mutual stages including data acquisition, processing, segmentation, outputting, and post-processing (not necessary for every system) (3-5, II). Digital data of the related structure can commonly be acquired via computerized tomography, conic-beam computerized tomography (CBCT), magnetic resonance imaging, and digital scanners $(6,7,11)$. During processing, a 3D model is virtually designed by means of computer-aided design software and saved as either standard tessellation language file or as another proprietary formats (4, 6, II). The process continues with the segmentation of the model into 2D layers (I). Subsequently, during outputting, sliced layers are stacked and fused together, thus processed data are printed out with the aid of additive-based printers (4). Last steps can be post-curing for complete polymerization and post-processing (7).

To the best knowledge of authors, the aforementioned common techniques have not been investigated extensively and therefore, data regarding this issue are scarce. In this review, it was aimed to set out the current status of most employed 
additive manufacturing techniques in prosthetic dentistry by comparing their advantageous and disadvantageous properties. Material options and working principles were also scrutinized.

\section{Am Techniques Extensively Used in Dentistry}

\section{Stereolithography}

SLA technique allows the solidification of liquid photopolymer by using ultraviolet (UV) laser source. After converting the 3D digital model into 2D cross-sections, a coherent light source is emitted in a particular manner by specific points located in a photosensitive resin-containing platform, thus inducing selective photo-polymerization and forming the very first layer. The platform is then lowered into the vat by a one-layer thickness, allowing the liquid to cover the first layer. The same process is then repeated over and over again, until the intended 3D model is physically manufactured $(I-5,7,8)$. Laser scan speed, power, and exposure time can become influential on resolution and curing time (I). The resultant model is then removed from the platform and placed into an UV oven, in order to complete the curing process and thereby to meet the required physical properties (3) (Table I).

\section{Selective Laser Sintering}

SLS technique allows the creation of 3D models by consolidating consecutive layers of powdered materials. In this method, a laser beam (usually carbon dioxide laser or neodymium-doped yttrium aluminum garnet laser) with a controlled path scans the powder to sinter (to partially melt) it by heating (I-5). High power of laser allows the fusion of powder through molecular diffusion (I). After scanning, the powder platform is lowered by a one-layer thickness, typically between 20-100 $\mu \mathrm{m}$ depending on the type of device, and a new layer of powder is sprayed onto the previous one. The process is repeated until the completion of the 3D model (9) (Table I).

\section{Selective Laser Melting}

SLM technique can be considered as a variation derived from SLS, as the same steps are applied in both techniques, with the main difference being that SLM completely melts the powder particles with powerful laser beam in order to form fully dense metallic models $(2,3,5)$ (Table I).

\section{Fused Deposition Modeling}

FDM technique, also known as fusion filament fabrication (FFF), has a widespread use among $A M$ technologies due to its relative inexpensiveness, high speed, and simplicity (I-4). This technique

\section{Main Points:}

- The AM techniques are very popular as they allow fast, precise, and cost-effective fabrication of highly customized functional structures for direct medical utilization.

- Of these AM techniques; stereo-lithography, selective laser sintering, selective laser melting, fused deposition modelling, and electron beam melting are in use in contemporary dentistry.

- These techniques have been developed for the fabrication of fixed prosthetic restorations, removable dentures, surgical guides, individualized implants, custom impression trays, and anatomical models. depends on the deposition of material in semi-liquid state through heat-producing nozzle that extrudes material in a specific path to form layer-by-layer a 3D model (7). The extrusion head heats the material. The molten viscosity has to be high enough to exhibit structural support and low enough to allow extrusion (to avoid clogging). In newer models, multiple nozzles that allow the use of multiple materials with different properties are present. Processing parameters such as raster width, layer thickness, and raster angle can become influential on the printing quality (I) (Table I).

\section{Electron Beam Melting}

From a technical standpoint, EBM and SLM share the same melting process of consecutive powder layers for fabricating the 3D model. However, EBM uses an electron beam instead of laser beam as a source of energy (2,5) (Table I).

\section{Current Applications in Prosthodontics}

\section{Printing of 3D casts}

One of the earliest implementations of AM technology into prosthodontics was to acquire 3D printed casts based on digital impressions, either for diagnostic purposes or to obtain definitive cast to manufacture dental prostheses (7). However, these printed casts have to show accuracy levels at least similar to that of conventional ones in order to be beneficial to the dental practice. Several studies exist in the literature that compare the accuracy of 3D printed casts, conventional casts, and the casts produced by subtractive method $(10,12,13)$. In this regard, Revilla-León et al. (I0) assessed the capability of 4 different RP technologies to duplicate a fully edentulous model including 7 implant analogues and to fabricate definitive casts for implant prostheses. It was highlighted that conventional dental stone casts could be accurately duplicated by using multi-jet printing and direct light processing technologies. Another study by Patzelt et al. (12) concluded that SLA technology was superior for the fabrication of dental casts; although all of the investigated casts (SLA-based and milled) indicated clinically acceptable accuracy. On the other hand, Alshawaf et al. (I3) found that 3D printed casts are inferior to their conventional counterparts in terms of surface finish, interproximal space replication, and accuracy.

\section{Fabrication of Surgical Guides}

Surgical guides are important during implantation for pinpointing the best location to drill. The placement of dental implants in the right position and at the right angle (surgical navigation) both increases the success rate of the procedure and minimizes the possibility of damage to the surrounding anatomical tissues $(2,3,14)$. During fabrication, initially, data of the patient are acquired with $\mathrm{CBCT}$ and intraoral scanner. Subsequently, digital processing and virtual planning through a computer-aided design (CAD) software are conducted (Figure I). Consequently, surgical guide is produced with the aid of a computer-aided manufacturing (CAM) device (8).

Surgical guide systems can be divided into static or dynamic. Stereolithography is the most commonly used technique as it allows the production of high-precision transparent guides which facilitates the visualization of anatomical structures during the surgical procedure. Stereolithographic guides can be referred as static because they do not allow modification of the virtually-planned position during implant surgery (8). 
TABLE I. Material options, technical data, and approximate accuracy level of commonly used additive manufacturing modalities

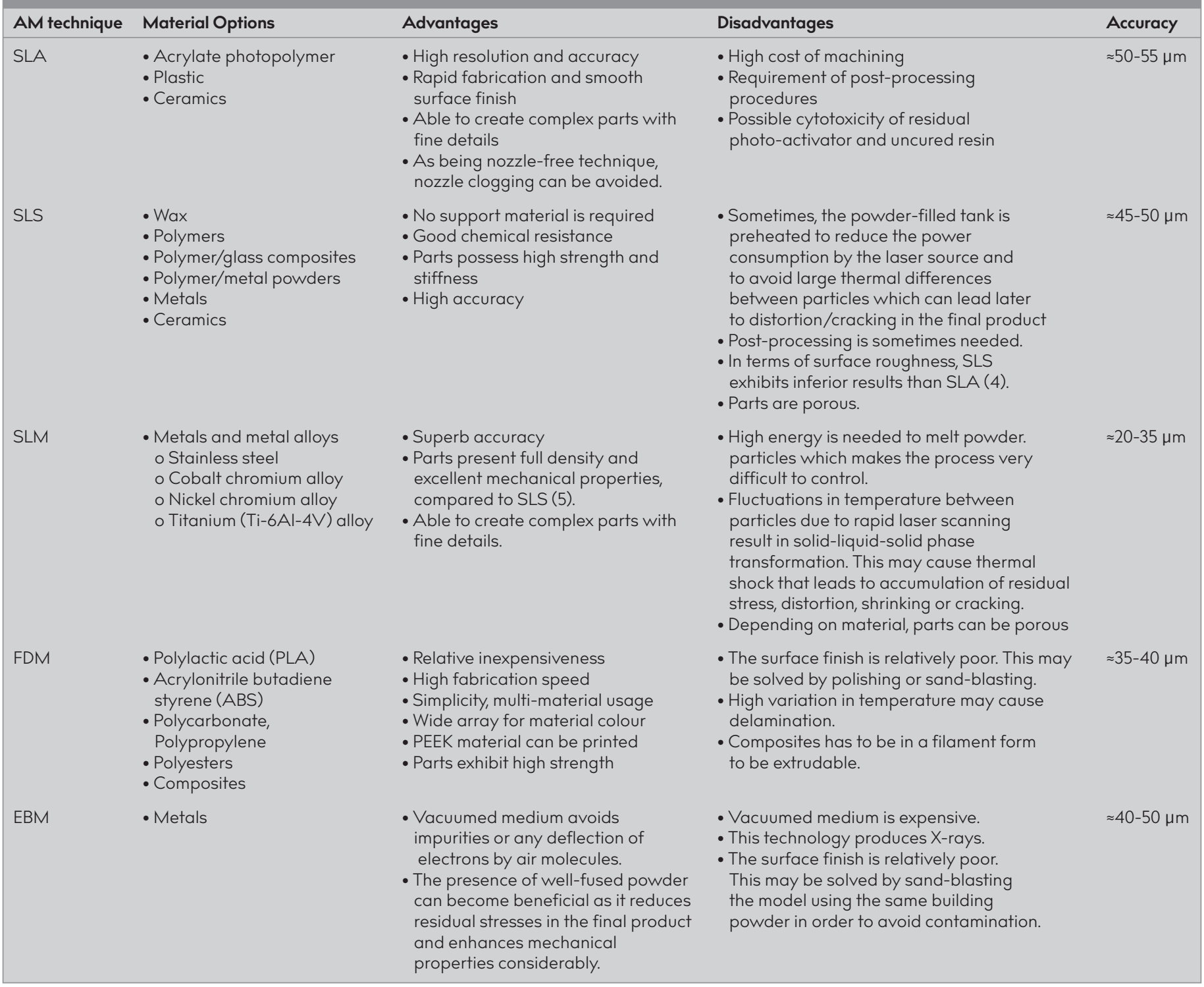
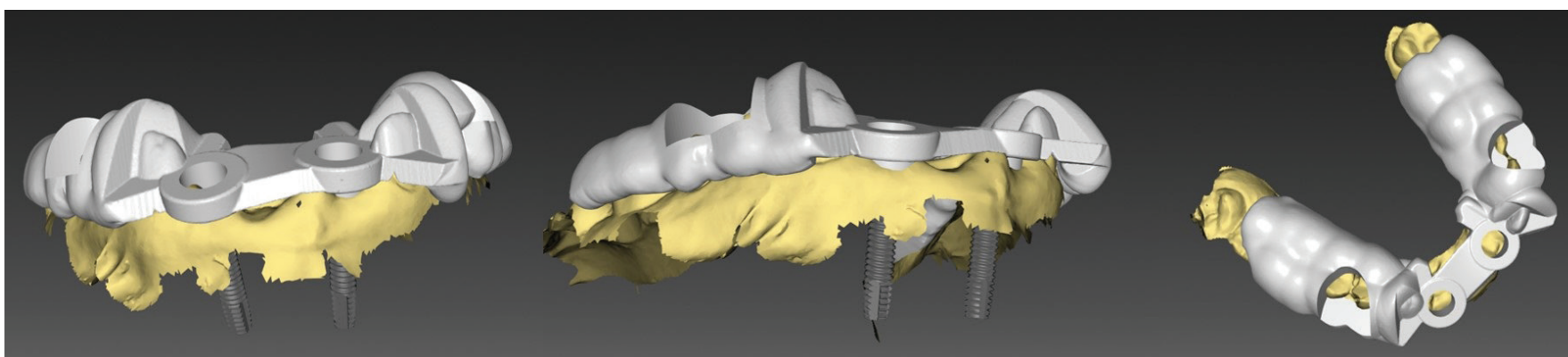

FIGURE I. Virtually designed surgical guide by correlating with CT data of patient (Design was conducted with a CAD software [InLab I5, Sirona Dental Systems, Bensheim, Germany])

\section{Fabrication of Custom Impression Trays}

The utilization of 3D polymer modeling technologies in prosthodontics omits some manual, time-consuming processes such as the fabrication of custom trays for taking conventional impressions (Figure 2). Moreover, by digitizing this process, a homogeneous space for the impression material can be achieved $(7,8)$. The ability of these trays for taking accurate, superior final impressions is also evident in the literature (I5). Additionally, the fabrication of custom trays designed especially for maxillofacial prosthetics have also been proven to be feasible (I6).

\section{Fabrication of Removable Complete Dentures}

Another earliest employment of AM technology is the fabrication of complete dentures in 1994, when Maeda et al. (17) described series of steps to manufacture a complete denture using lightcured resin with the assist of an SLA machine. Since then, there 


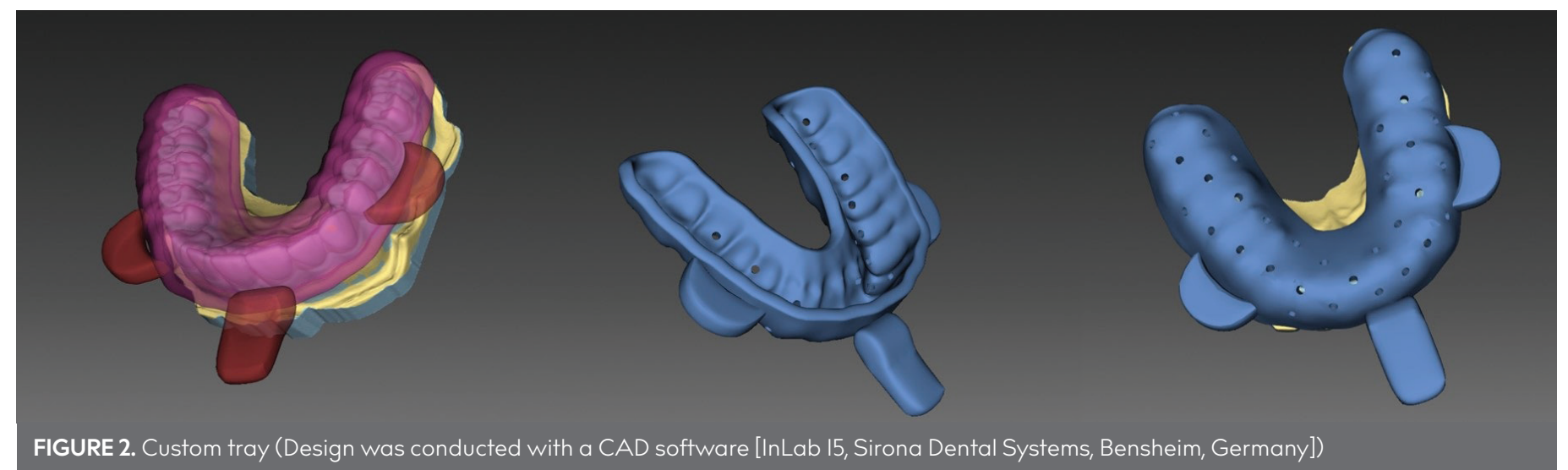

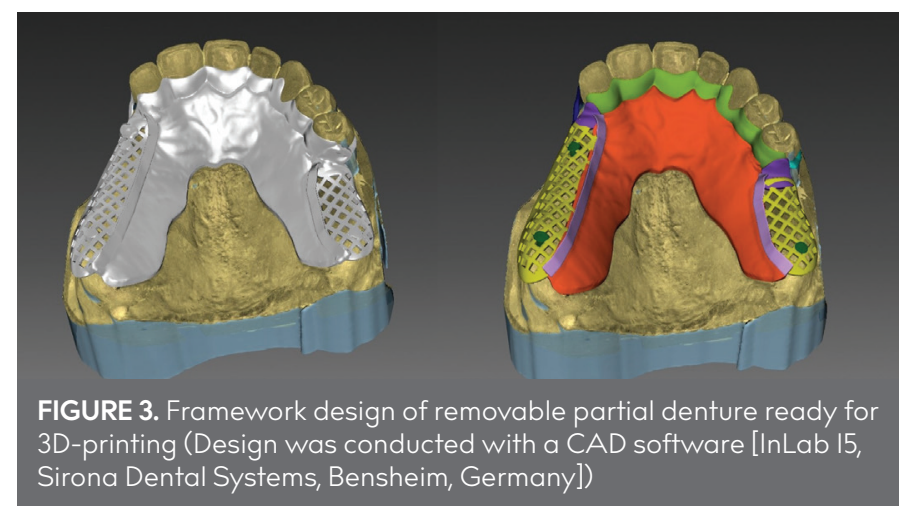

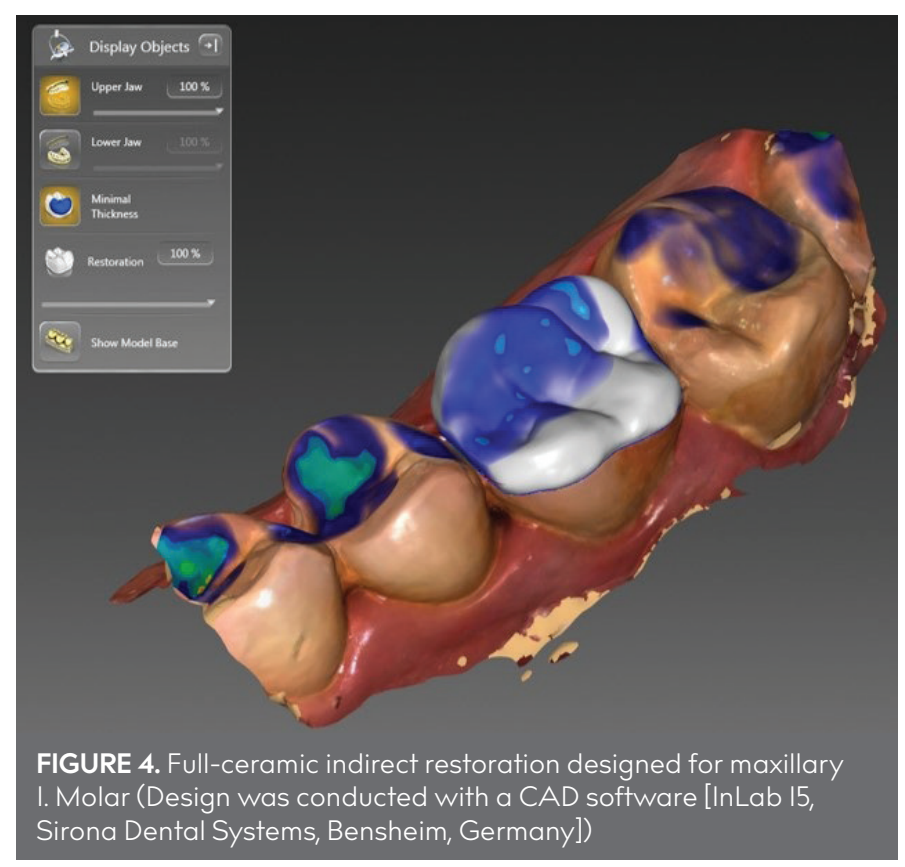

have been several depictions of different methods to incorporate AM technologies into the fabrication of removable complete dentures (7). There are several studies that investigated complete dentures fabricated with additive, subtractive, and conventional manners (18-20). According to Davda et al. (18), AM technique is superior to the conventional methods in terms of precision and accuracy. Inokoshi et al. (19) stated that the use of AM to produce trial wax dentures presents comparable results with conventional technique, and although further improvements are needed; applying RP technique to obtain trial dentures seems to be a promising method. To the best knowledge of authors, manufacture of dentures by using CAD/CAM techniques are considered to be a valid method as these dentures provide equal or better fit, analogous biocompatibility, improved mechanical properties, and high patient/clinician satisfaction. The feasibility of employing AM techniques to manufacture definitive dentures is, however, questionable. A study by Kalberer et al. (20) reinforced this hypothesis by reporting that milled dentures were superior to printed ones in terms of trueness of intaglio surface.

\section{Fabrication of Interim Dental Restorations}

Different AM methods to manufacture interim crowns, bridges, or even fixed implant dentures have been described in the literature $(8,21,22)$. Additionally, there are several studies that compared $3 \mathrm{D}$ printed interim restorations with their milled and conventional counterparts. These studies supported the usability of such interim restorations based on their sufficient mechanical properties and acceptable marginal-internal fit values $(23,24)$. However, there is a necessity for additional studies regarding the polymers used in AM in terms of biocompatibility and long-term viability (8).

\section{Printing of Castable Patterns}

Several commercially available castable polymers are in use for AM technologies. These polymers are shaped with rapid tooling to produce patterns for different restorations which can be casted using conventional methods to obtain metal or pressed lithium disilicate restorations (7). Several descriptions exist in the literature for employments of 3D printed patterns for the fabrication of several types of restorations such as inlays, onlays, crowns and bridges, frameworks for partial dentures, frameworks for implant-supported prostheses, and even maxillofacial prostheses $(9,25-30)$. Though available, the aforementioned applications of printed patterns have to be investigated in order to verify their viability for replacing with conventional techniques. Inlays and onlays produced from printed patterns were found to have marginal and internal fit values that are clinically acceptable $(27,28)$. The marginal and internal fit investigations of casted, SLA printed-, and milled-patterns were conducted by Kim et al. (3I). They concluded that all test groups have indicated clinically acceptable and comparable marginal-internal fit valves, except milled copings. The fit of removable partial denture frameworks has also been investigated in the literature, and despite the lack of sufficient clinical trials, the available evidence supports the fact that printed patterns provide enough fit to the frameworks for clinical applications (32). Regarding the frameworks for implant-supported fixed dentures, Alikhasi et al. (30) have found that although frameworks casted from printed pat- 
terns were inferior to the ones produced from milled patterns in terms of retention values; the amount of retention achieved by both groups was clinically acceptable.

Polyetheretherketone (PEEK) is a thermoplastic, semi-crystalline polymer belonging to a family of linear aromatic polymers containing ether and ketone linkages $(33,34)$. It presents acceptable composition of properties including good biocompatibility, chemical resistance, good mechanical properties, and a low elastic modulus (3-4 GPa) which is analogous to the human cortical bone's (14 GPa) (34). Some of the novel implementations of 3D printed polymers in dentistry is the indirect use of rapid prototyping to produce PEEK frameworks for the partial dentures through thermo-pressing of printed patterns. According to a study by Negm et al. (33), milled PEEK frameworks presented significantly better trueness in comparison to the ones fabricated with indirect AM technique. Nevertheless, both techniques have been found to possess enough fit values from a clinical standpoint.

\section{Fabrication of Dental Implants}

The success of dental implants relies heavily on the location of important landmarks (mandibular nerve canal and maxillary sinus) and on the anatomic features of the alveolar bone, mainly the presence of ample bone tissue. Therefore, the idea of manufacturing individualized dental implants with specific dimensions for each patient can improve success ratios in patients with relatively inadequate bone. The aforementioned concept has already become a feasible reality with the advent of $A M$ as the incorporation of rapid manufacturing techniques into implant dentistry allows the manufacturing of highly customized dental implants $(2,3,35)$. The introduction of SLM and EBM to the implant dentistry has unlocked several possibilities for the development of dental implants. Aside from customization, the concepts of osseointegration, titanium alloys, implants with special geometries are all aspects to be exploited thanks to the technologies that rapid manufacturing offers. 3D printed implants have features like micro-roughness, nano-roughness hydrophilic surfaces, and controlled porosity which can all improve the osseointegration process (36). Furthermore, the implementation of 3D printed implants has already yielded good clinical results $(37,38)$. An additional improvement that AM has to offer in the implantology sector is the use of a new additively manufactured implant material based on $\mathrm{Ti}-42 \mathrm{Nb}$ alloy, as a substitute for the commercially available titanium alloy (Ti-6Al-4V). Schulze et al. (39) proved that the printed implants from this alloy have lower Young modulus when compared with standard implant materials, thus improving the elastic compatibility with human bone.

The mixture of above-mentioned characteristics also makes PEEK a viable alternative to titanium and ceramics for applications in implant dentistry $(3,34)$. Mounir et al. (38) have conducted a study to evaluate highly customized 3D printed titanium and PEEK implants for the rehabilitation of severely atrophic anterior maxilla. The results obtained from a 12-month follow-up showed the success of both titanium and PEEK implants. However, the use of PEEK as an AM material is fairly recent and although it seems promising; the current evidence in the literature that supports the use of 3D printed PEEK in implant dentistry is very scarce.

The production of zirconia implants through AM is also present in the literature (5). It has been demonstrated that printed cus- tomized zirconia implants are feasible and can present acceptable dimensional accuracy along with mechanical properties close to the conventionally manufactured ones (40). Additionally, with the aid of advantages that material extrusion techniques can offer, it is possible to create zirconia-based customizable implants. The deposition of two different materials can produce implants in both dense and porous structures, which in turn can reduce the elastic modulus and favour osteointegration thanks to the presence of pores (4I).

\section{Fabrication of Metal Frameworks for Fixed Prostheses and Re- movable Partial Dentures}

Lost wax technique and the milling technique are both considered to be the traditional ways to produce metal frameworks for fixed partial restorations, removable partial dentures (Figure 3), and implant-supported dentures. However, with the advent of additive manufacturing, the limitations of the milling technique can be omitted as AM techniques waste minimum amount of material and can produce models with greater accuracy and detail $(3,4,9,11)$.

The mechanical properties, marginal-internal fit, and dimensional accuracy of additively manufactured metal frameworks were all investigated in the literature. The mechanical properties of the printed $\mathrm{Cr}$-Co copings were found to be greater than those produced with milling or conventional techniques (42). Regarding the discrepancy values and dimensional accuracy, Akçin et al. (43) have found that regardless of unit number, implant-supported frameworks fabricated with SLM technique had similar values to the ones fabricated with casting technique and better values than the milled ones. The use of $A M$ to produce metal frameworks for removable partial dentures and for complete dentures has become a useful alternative to the milling and conventional casting techniques as it produces effective prostheses with acceptable clinical results $(44,45)$. As for implant-supported denture frameworks, several studies have revealed the practicality of AM methods in producing frameworks that have low misfit values and favourable outcomes (46).

\section{Fabrication of Full-Ceramic Fixed Prostheses}

The widespread use of ceramic materials in the dental practice can be attributed to a specific set of features that they possess such as excellent biocompatibility, chemical stability, decent mechanical properties, and high aesthetics (Figure 4). However, the brittle nature of ceramics dictates a very strict control over the manufacturing process to acquire dental pieces with convenient mechanical properties. It is because of such properties that ceramics were only lately introduced into additive manufacturing. The high melting point, development of different phases in such high temperatures, and the formation of cracks during the cooling stage due to thermal shocks are all factors that increase the difficulty of processing ceramics through additive techniques (5, II). The current techniques used for the additive manufacturing of zirconia are material extrusion/jetting and stereolithography for the production of a green body which will be subjected later to post-processing and sintering (5). It has been demonstrated in the literature that by using the aforementioned methods, it is possible to produce zirconia parts with post-sintering densities (ranging between $96.9 \%$ and $99 \%$ ), high dimensional accuracy, and similar mechanical properties to conventionally-manufactured zirconia (II). Problems like anisotropic roughness can be addressed with post-polishing. However, complications like 
clogged nozzles that can produce process-related defects, and high abrasion of the machine components are still a cause for concern (47).

In the literature, the rapid manufacturing of alumina ceramics has also been examined. Through techniques like FDM, it is possible to print alumina parts with up to $99 \%$ density, homogenous microstructure, and improved mechanical properties. Methods like vacuum infiltration can be used on the green bodies to improve density and strength (48). Dehurtevent et al. (49) have conducted a study that compared stereolithography-manufactured alumina ceramics to the subtractive-manufactured ones. The results indicated the possibility of printing alumina with anisotropic shrinkage, density, and flexural strength similar to those of a subtractive-manufactured ceramic. Wilkes et al. (50) were able to manufacture objects from a mixture containing 41.5 wt.\% zirconia and 58.5 wt.\% alumina by using SLM technology. The produced models had good mechanical properties and density percentage of almost 100\% without the need for any post-processing or sintering. However, they also pointed out some challenges that must be addressed including thermal stresses and surface roughness.

\section{CONCLUSION}

AM technology started a new era in the rapid fabrication of net-shaped products by automating stages. As evidenced by the above-mentioned studies, different approaches and different biomaterials have been introduced for precise fabrication of complex-shaped individualized patterns and prototypes with superior print quality in the layer-by-layer manner.

Currently, with the help of this cost-effective innovation in which the amount of residual material is negligible, elaborate dental crowns, removable dentures, surgical guides, individualized implants, custom impression trays, and anatomical models can be manufactured. However, scientific documentation regarding these systems is somewhat scarce and further studies are needed.

The upcoming trends for practitioners will be the use of AM-manufactured root-analogue implants that can be inserted immediately after tooth-extraction and the milling of all restorations (especially zirconia-based ones) by in-house CAD/ CAM centres.

Peer-review: Externally peer-reviewed.

Author Contributions: Concept - Ö.Ö., A.A.; Design - Ö.Ö., A.A.; Supervision - Ö.Ö.; Resources - Ö.Ö., A.A.; Materials - A.A.; Data Collection and/or Processing - A.A.; Analysis and/or Interpretation - Ö.Ö.; Literature Search - A.A.; Writing Manuscript - Ö.Ö., A.A.; Critical Review - Ö.Ö., A.A.; Other - Ö.Ö., A.A.

Conflict of Interest: Authors have no conflicts of interest to declare.

Financial Disclosure: The authors declared that this study has received no financial support.

\section{REFERENCES}

I. Wang $X$, Jiang M, Zhou Z, Gou J, Hui D. 3D printing of polymer matrix composites: A review and prospective. Compos Part B-Eng 2017; II0: 442-58. [Crossref]
2. Javaid $M$, Haleem A. Current status and applications of additive manufacturing in dentistry: A literature-based review. J Oral Biol Craniofac Res 2019; 9(3): 179-85. [Crossref]

3. Dawood A, Marti BM, Sauret-Jackson $V$, Darwood A. 3D printing in dentistry. Br Dent J 2015; 219(II): 521. [Crossref]

4. Dizon JR, Espera Jr AH, Chen Q, Advincula RC. Mechanical characterization of 3D-printed polymers. Addit Manuf 2018; 20: 44-67. [Crossref]

5. Galante R, Figueiredo-Pina CG, Serro AP. Additive manufacturing of ceramics for dental applications: A review. Dent Mater 2019; 35(6): 825-46. [Crossref]

6. Alghazzawi TF. Advancements in CAD/CAM technology: Options for practical implementation. J Prosthodont Res 2016; 60(2): 72-84. [Crossref]

7. Revilla-León M, Özcan M. Additive manufacturing technologies used for processing polymers: current status and potential application in prosthetic dentistry. J Prosthodont 2019; 28(2): 146-58. [Crossref]

8. Revilla-León M, Sadeghpour M, Özcan M. An update on applications of 3D printing technologies used for processing polymers used in implant dentistry. Odontology 2019. Doi: 10.1007/s10266-0190044I-7. [Epub ahead of print]. [Crossref]

9. Revilla-León M, Meyer MJ, Özcan M. Metal additive manufacturing technologies: literature review of current status and prosthodontic applications. Int J Comput Dent 2019; 22(I): 55-67.

10. Revilla-León M, Gonzalez-Martín Ó, Pérez López J, Sánchez-Rubio $\mathrm{JL}$, Özcan M. Position accuracy of implant analogs on 3D printed polymer versus conventional dental stone casts measured using a coordinate measuring machine. J Prosthodont 2018; 27(6): 560-67. [Crossref]

II. Javaid $M$, Haleem A. Additive manufacturing applications in medical cases: A literature based review. Alexandria Med J 2018; 54(4): 4II-22. [Crossref]

12. Patzelt SB, Bishti S, Stampf S, Att W. Accuracy of computer-aided design/computer-aided manufacturing-generated dental casts based on intraoral scanner data. J Am Dent Assoc 20|4; 145(II): ||3340. [Crossref]

13. Alshawaf B, Weber HP, Finkelman M, El Rafie K, Kudara Y, Papaspyridakos P. Accuracy of printed casts generated from digital implant impressions versus stone casts from conventional implant impressions: A comparative in vitro study. Clin Oral Implants Res 2018; 29(8): 835-42. [Crossref]

14. Tatakis DN, Chien HH, Parashis AO. Guided implant surgery risks and their prevention. Periodontol 2000 2019; 8I(I): 194-208. [Crossref]

15. Liu Y, Di P, Zhao Y, Hao Q, Tian J, Cui H. Accuracy of multi-implant impressions using 3D-printing custom trays and splinting versus conventional techniques for complete arches. Int J Oral Maxillofac Implants 2019. Doi: 10.11607/jomi.7049. [Epub ahead of print] [Crossref]

16. Huang Z, Wang XZ, Hou YZ. Novel method of fabricating individual trays for maxillectomy patients by computer-aided design and rapid prototyping. J Prosthodont 2015; 24(2): II5-20. [Crossref]

17. Maeda Y, Minoura M, Tsutsumi S, Okada M, Nokubi T. A CAD/CAM system for removable denture. Part I: Fabrication of complete dentures. Int J Prosthodont 1994; 7(I): 17-21.

18. Davda K, Osnes C, Dillon S, Wu J, Hyde P, Keeling A. An investigation into the trueness and precision of copy denture templates produced by rapid prototyping and conventional means. Eur J Prosthodont Restor Dent 2017; 25(4): 186-92.

19. Inokoshi M, Kanazawa M, Minakuchi S. Evaluation of a complete denture trial method applying rapid prototyping. Dent Mater J 2012; 3I(I): 40-6. [Crossref]

20. Kalberer N, Mehl A, Schimmel M, Müller F, Srinivasan M. CAD-CAM milled versus rapidly prototyped (3D-printed) complete dentures: 
An in vitro evaluation of trueness. J Prosthet Dent 2019; I2I(4): 63743. [Crossref]

21. Revilla-León M, Fountain J, Piedra Cascón W, Özcan M, Zandinejad A. Workflow description of additively manufactured clear silicone indexes for injected provisional restorations: A novel technique. J Esthet Restor Dent 2019 ;3I(3): 213-21. [Crossref]

22. Oh JH, An X, Jeong SM, Choi BH. A digital technique for fabricating an interim implant-supported fixed prosthesis immediately after implant placement in patients with complete edentulism. J Prosthet Dent 2019; 12I(I): 26-31. [Crossref]

23. Alharbi N, Alharbi S, Cuijpers VMJI, Osman RB, Wismeijer D. Three-dimensional evaluation of marginal and internal fit of $3 D$-printed interim restorations fabricated on different finish line designs. J Prosthodont Res. 2018; 62(2): 218-26. [Crossref]

24. Digholkar S, Madhav VN, Palaskar J. Evaluation of the flexural strength and microhardness of provisional crown and bridge materials fabricated by different methods. J Indian Prosthodont Soc 2016; 16(4): 328-34. [Crossref]

25. Ishida Y, Miyasaka T. Dimensional accuracy of dental casting patterns created by 3D printers. Dent Mater J 2016; 35(2): 250-56. [Crossref]

26. Williams RJ, Bibb R, Rafik T. A technique for fabricating patterns for removable partial denture frameworks using digitized casts and electronic surveying. J Prosthet Dent 2004; 9I(I): 85-8. [Crossref]

27. Revilla-León M, Olea-Vielba M, Esteso-Saiz A, Martínez-Klemm I, Özcan M. Marginal and internal gap of handmade, milled and $3 d$ printed additive manufactured patterns for pressed lithium disilicate onlay restorations. Eur J Prosthodont Restor Dent 2018; 26(I): $31-8$.

28. Homsy FR, Özcan M, Khoury M, Majzoub ZAK. Marginal and internal fit of pressed lithium disilicate inlays fabricated with milling, 3D printing, and conventional technologies. J Prosthet Dent 2018; II9(5): 783-90. [Crossref]

29. Sykes LM, Parrott AM, Owen CP, Snaddon DR. Applications of rapid prototyping technology in maxillofacial prosthetics. Int J Prosthodont 2004; 17(4): 454-59.

30. Alikhasi M, Rohanian A, Ghodsi S, Kolde AM. Digital versus conventional techniques for pattern fabrication of implant-supported frameworks. Eur J Dent 2018; 12(I): 71-6. [Crossref]

31. Kim SB, Kim NH, Kim JH, Moon HS. Evaluation of the fit of metal copings fabricated using stereolithography. J Prosthet Dent 2018; 120(5): 693-98. [Crossref]

32. Arnold C, Hey J, Schweyen R, Setz JM. Accuracy of CAD-CAM-fabricated removable partial dentures. J Prosthet Dent 2018; II9(4):58692. [Crossref]

33. Negm EE, Aboutaleb FA, Alam-Eldein AM. Virtual evaluation of the accuracy of fit and trueness in maxillary poly(etheretherketone) removable partial denture frameworks fabricated by direct and indirect CAD/CAM techniques. J Prosthodont 2019. [Crossref]

34. Honigmann P, Sharma N, Okolo B, Popp U, Msallem B, Thieringer FM. Patient-specific surgical implants made of 3D printed peek: Material, technology, and scope of surgical application. Biomed Res Int 2018; 2018: 4520636. [Crossref]

35. Oliveira TT, Reis AC. Fabrication of dental implants by the additive manufacturing method: A systematic review. J Prosthet Dent 2019. Pii: S0022-3913(19)30096-4.

36. Hyzy SL, Cheng A, Cohen DJ, Yatzkaier G, Whitehead AJ, Clohessy $\mathrm{RM}$, et al. Novel hydrophilic nanostructured microtexture on direct metal laser sintered Ti-6Al-4V surfaces enhances osteoblast response in vitro and osseointegration in a rabbit model. $J$ Biomed Mater Res A 2016; 104(8): 2086-98. [Crossref]

37. Tunchel S, Blay A, Kolerman R, Mijiritsky E, Shibli JA. 3D printing/ additive manufacturing single titanium dental implants: a prospective multicenter study with 3 years of follow-up. Int J Dent 2016; 2016: 8590971. [Crossref]

38. Mounir M, Atef M, Abou-Elfetouh A, Hakam MM. Titanium and polyether ether ketone (PEEK) patient-specific sub-periosteal implants: two novel approaches for rehabilitation of the severely atrophic anterior maxillary ridge. Int J Oral Maxillofac Surg 2018; 47(5): 658-64. [Crossref]

39. Schulze C, Weinmann M, Schweigel C, Keßler O, Bader R. Mechanical properties of a newly additive manufactured implant material based on Ti-42Nb. Materials (Basel) 20I8; II(I): el24. [Crossref]

40. Osman RB, van der Veen AJ, Huiberts D, Wismeijer D, Alharbi N. 3D-printing zirconia implants; a dream or a reality? An in-vitro study evaluating the dimensional accuracy, surface topography and mechanical properties of printed zirconia implant and discs. J Mech Behav Biomed Mater 2017; 75: 521-28. [Crossref]

4I. Scheithaver U, Weingarten S, Johne R, Schwarzer E, Abel J, Richter $\mathrm{HJ}$, et al. Ceramic-based 4D components: Additive manufacturing (AM) of ceramic-based functionally graded materials (FGM) by thermoplastic 3D printing (T3DP). Materials (Basel). 2017; 10(12): el368. [Crossref]

42. Øilo M, Nesse H, Lundberg OJ, Gjerdet NR. Mechanical properties of cobalt-chromium 3-unit fixed dental prostheses fabricated by casting, milling, and additive manufacturing. J Prosthet Dent 2018; 120(I): 156.el-7. [Crossref]

43. Akçin ET, Güncü MB, Aktaș G, Aslan Y. Effect of manufacturing techniques on the marginal and internal fit of cobalt-chromium implant-supported multiunit frameworks. J Prosthet Dent 2018; 120(5): 7|5-20. [Crossref]

44. Tregerman I, Renne W, Kelly A, Wilson D. Evaluation of removable partial denture frameworks fabricated using 3 different techniques. J Prosthet Dent 2019. [Crossref]

45. Kanazawa M, Iwaki M, Minakuchi S, Nomura N. Fabrication of titanium alloy frameworks for complete dentures by selective laser melting. J Prosthet Dent 20|4; ||2(6): |44|-47. [Crossref]

46. Revilla-León M, Ceballos L, Martínez-Klemm I, Özcan M. Discrepancy of complete-arch titanium frameworks manufactured using selective laser melting and electron beam melting additive manufacturing technologies. J Prosthet Dent 2018; 120(6): 942-47. [Crossref]

47. Xing H, Zou B, Li S, Fu X. Study on surface quality, precision and mechanical properties of 3D printed $\mathrm{ZrO} 2$ ceramic components by laser scanning stereolithography. Ceram Int 2017; 43(18): 16340-7. [Crossref]

48. Maleksaeedi S, Eng H, Wiria FE, Ha TMH, He Z. Property enhancement of 3D-printed alumina ceramics using vacuum infiltration. J Mater Process Technol 2014; 2|4(7): I30I-6. [Crossref]

49. Dehurtevent M, Robberecht L, Hornez JC, Thuault A, Deveaux E, Béhin P. Stereolithography: A new method for processing dental ceramics by additive computer-aided manufacturing. Dent Mater 2017; 33(5): 477-85. [Crossref]

50. Wilkes J, Hagedorn YC, Meiners W, Wissenbach K. Additive manufacturing of $\mathrm{ZrO} 2-\mathrm{Al} 2 \mathrm{O} 3$ ceramic components by selective laser melting. Rapid Prototyp J 2013; 19(I): 51-7. [Crossref] 